\title{
WHY DO WE NEED THE NOTION OF WILL?*
}

\author{
Rafael Graebin Vogelmann** \\ http://orcid.org/0000-0001-9582-8465 \\ rafael.vog@gmail.com
}

\begin{abstract}
It is commonly held that the goals at which an action aims are specified by the pro-attitude/belief pairs in light of which the action seems appealing to the agent. I argue that the existence of multiple-incentives cases (i.e., cases in which the agent has more than one incentive to act but in which her motive corresponds to only one of these incentives) shows this thesis to be false. In order to account for such cases we have to ascribe to agents the capacity to actively determine the goals at which their actions aim. I refer to this capacity as the agent's "will". Agents endowed with a will are capable not only of determining their own behavior but also their motives. I conclude that the existence of multiple-incentives cases shows that agents have this capacity.
\end{abstract}

Keywords Will, goals, motives, desires, incentives.

RESUMO É comumente sustentado que os fins visados por uma ação são especificados pelos pares atitude/crença à luz dos quais a ação parece atrativa para o agente. Eu argumento que a existência de casos de múltiplos incentivos (isto é, casos nos quais o agente tem mais de um incentivo para agir mas nos quais seu motivo corresponde a apenas um desses incentivos) mostra que essa tese é falsa. De maneira a dar conta desses casos devemos atribuir a agentes a capacidade de determinar ativamente os fins visados por suas ações. Refiro-me a essa capacidade como a "vontade" do agente. Agentes dotados de

* Artigo submetido em 12/04/2019. Aprovado em 04/06/2019.

** Universidade Federal do Rio Grande do Sul. Porto Alegre, RS, Brasil.

KRITERION, Belo Horizonte, n 146, Ago./2020, p. 523-544 
vontade são capazes não apenas de determinar seu próprio comportamento mas também seus motivos. Concluo que a existência de casos de incentivos múltiplos mostra que agentes têm essa capacidade.

Palavras-chave Vontade, fins, motivos, desejos, incentivos.

\section{Introduction}

A statement of the form "agent $S$ did action $A$ with the intention of $G$ " informs us about the goal at which action $A$ was aimed - it has the same content as "agent $S$ did action $A$ in order to $G$ ". For instance, to say that "she added sage to the stew with the intention of improving its taste" is just to say that she added the sage in order to improve the stew's taste. It is commonly held that the goal at which an action is aimed is specified by the pro-attitude/belief pair in light of which the action seems appealing to the agent. Thus, "she added the sage to the stew in order to improve its taste" is correct if the agent wanted to improve the taste of the stew and believed that adding sage to the stew would do just that.

This view is strongly associated with Davidson ${ }^{1}$ but it is shared by a number of philosophers. As a matter of fact, I shall argue that it is entailed by a widely shared view about motivation. This view is composed by three thesis: (A) we are directly moved by pro-attitude/belief pairs: a pair composed by a pro-attitude towards $G$ and the belief that doing $A$ is conductive to $G$ (i.e., a pro- $A$ pair) motivates us to perform $A$; (B) pro-attitude/belief pairs differ in strength and when an agent has several pro- $A$ pairs these combine their strengths to produce a stronger motivation to perform $A$ (I refer to this as the thesis of compositionality $)^{2}$ and (C) when faced with appealing but incompatible alternative actions we perform the action that we are more strongly motivated to perform. I refer to this set of thesis as the Hydraulic $\mathrm{Model}^{3}$ of our motivational psychology because it is naturally understood as a way of expressing the view

1 Davidson claims that we can explain an action by indicating "what it was about the action that appealed" to the agent, that we do so by presenting the "primary reason why the agent performed the action" which is nothing but a pro-attitude/belief pair (Davidson, 1980, pp. 3-4) and that to "know a primary reason why someone acted as he did is to know an intention with which the action was done" (Davidson, 1980, p. 7).

2 It is not part of this thesis that compositionality is linear, so that, for instance, if two desires of equal strength combine then the resulting motivation is twice as strong as each of them. All that follows from it is that if desires $D_{1}$ and $D_{2}$ are equally strong, then the motivation produced by set $\left\{D_{1}, D_{3}\right\}$ is to some degree stronger than the one produced by set $\left\{D_{2}\right\}$. These sets of desires are what Mele calls the "motivational base" of the motivation to act (see Mele, 1992, pp. 58-60).

3 The phrase comes from McDowell (2002, p. 213) and Wallace (2006, p. 55). 
that our behavior is determined by the tug of war between impulses or forces within us.

The Hydraulic Model is explicitly upheld by philosophers such as Frankfurt and Velleman ${ }^{4}$ and many others are implicitly committed to it. For instance, this view is what is behind Schroeder's claim that since "your desires are what motivate you to act" you can act according to your moral reasons only to the extent you have a "collection of desires whose strengths match the weights of [your] independently existing reasons" (Schroeder, 2007, p. 169). A case can also be made for the claim that Hume upheld this view, but it is important to notice that the Hydraulic Model is compatible with an anti-Humean theory of motivation. Dancy (2000, pp. 85-7) describes (but does not subscribe to) a view he calls pure cognitivism. According to this view beliefs produce motivation directly (and desires are identified with the state of being motivated). The motivations produced by different beliefs, however, differ in strength and when there is a conflict of motivation, we are moved by the strongest one. Pure cognitivism is, therefore, an anti-Humean version of the Hydraulic Model.

My primary goal in this paper is to reject the view that the goals our actions aim at are specified by the pro-attitude/belief pairs that render the action appealing to the agent. My argument is simple: there are multipleincentives cases, i.e., cases in which the agent has more than one incentive to act but in which her motive correspond to only one of these incentives, and the view that our actions' goals are specified by our pro-attitude/belief pairs is incompatible with the existence of these cases. This conclusion has three important consequences. First, if the goals our actions aim at are not passively determined by the pro-attitude/belief pairs that render them appealing, then they must be somehow actively determined by the agent. I refer to the capacity to actively determine the goals one's actions aim at as the agent's "will". If my arguments are successful, therefore, they show that we need the notion of the will in order to account for multiple-incentives cases. Second, as I shall argue, in actively determining the goals their actions aim at agents actively determine their motives. Therefore, the existence of multiple-incentives cases shows that agents are capable not only of determining their own behavior but also of determining their motives. Third, given that, as I shall argue, the view that the goals at which our actions aim are specified by our pro-attitude/belief pairs is entailed by the Hydraulic Model, it follows that we should reject the this model and with it the idea that we are moved by pro-attitude/belief pairs. 
In section 2, I discuss the notions of motive and incentive and, in section 3, I introduce the notion of multiple-incentives cases. In section 4, I argue that the Hydraulic Model entails the view that the goals our actions aim at are determined by the pro-attitude/belief pairs that render them appealing and that this view is incompatible with the existence of multiple-incentives cases. Sections 5 through 7 address some attempts to avoid the conclusions drawn at section 4. Finally, in section 8, I argue that introducing the notion of the will allow us to account for multiple-incentives cases.

\section{Motives and Incentives}

Attributions of motives usually take the form "person $P$ did action $A$ because $M$ ", as in "she ran because her bus was about to leave" or "she added sage to the stew because it would improve its taste". Statements of this form ascribe motives when the fact that fills in the $M$-slot renders the action intelligible as an action aimed at a particular goal. If I say something like "she moved her leg because I hit her knee" or "he yawned because the person next to him yawned" I am simply asserting the cause of the action, not ascribing a motive to the agent. Usually the following entailment holds:

MOTIVE-GOAL LINK: If $M$ is the motive for which agent $P \operatorname{did} A$, then $A$ aims at a goal $G$ and $M$ is part of what explains why doing $A$ is an effective or necessary means to $G{ }^{5}$

Thus, for instance, if "she ran because her bus was about to leave" is a correct motive ascription, then the action of running aims at a goal and the fact that the bus was about to leave helps explain why running was conductive to that goal. We can easily infer that the action of running was aimed at catching the bus and the fact that the bus was about to leave explains why running was necessary to the achievement of that goal. This connection between motive ascription and the goal at which the action aimed is made even clearer if we pay attention to the fact that both "she ran because the bus was about to leave"

5 When I say that the entailment "usually holds" I mean it. There are a number of exceptions to the motive-goal link. Sometimes an agent's motive explain her acting with a view to a particular goal instead of rendering intelligible the performance of a particular action in light of the goal it aimed at (that is the case in "she ran because she had an appointment"). And it seems that in cases of error, in which the agent acts under the belief that something is the case when it is not, her motive must be identified with the fact that she had the belief in question (as in "she run because she thought the bus was about to leave") and this fact does not explain why performing the action was a means to the agent's goal. Nevertheless, the motive-goal link holds in relation to an important class of motive attributions, namely, those motive attributions in which the motive corresponds to an incentive to act that the agent recognizes. I will introduce the notion of an incentive presently and in what follows I will focus on this class of motive attributions. 
and "she ran in order to catch the bus (which was about to leave)" are equally satisfactory and roughly equivalent answers to the question "why did she run?", even though the latter is not an ascription of motive but simply states the goal at which the action was directed.

The correction of a motive ascription also entails that the agent (i) has a pro-attitude towards the goal $G$ at which her action $A$ aims (she either desires, wants, prizes, is inclined towards $G$, etc.), (ii) believes that performing $A$ is either a means to $G$ or constitutes $G$ and (iii) puts that pro-attitude and that belief together in the appropriate way. ${ }^{6}$ Thus, for instance, if "she ran because the bus was about to leave" is a correct motive ascription, then the agent in this example wants to catch the bus and believes running to be an effective means to achieve that goal. ${ }^{7}$

Let me now introduce the notion of an incentive:

INCENTIVES: If fact $I$ is an incentive for agent $P$ to perform action $A$, then $A$ is an available course of action for $P, P$ has a pro-attitude towards $G$ and $I$ is part of what explains why doing $A$ is an effective or necessary means to $G$.

Thus, for instance, the fact that the bus is about to leave is an incentive for the agent in our example to run because she wants to catch the bus and the fact that the bus is about to leave explains why running is a necessary means to catch the bus.

An agent recognizes an incentive $I$ for doing $A$ when she realizes that, in light of fact $I$, doing $A$ will promote (or is necessary to promote) goal $G$, which she happens to desire or want or prize, etc. Thus an agent recognizes the fact that the bus is about to leave as an incentive for her to run when she realizes that, in light of the fact that the bus is leaving, running is a necessary means to catch the bus (which is something she wants to do). If an agent recognizes

6 This view is shared by a number of philosophers, such as Nagel (1978, pp. 29-30), McDowell (1978, p. 15), Smith (1994, p. 116) and Dancy (2000, p. 85). As for the need to put the attitude and the belief together see Schueler (2009, pp. 107-8): just as one can believe that $p \rightarrow q$ and that $p$ without believing that $q$ because one has not put those two beliefs together, one cannot perform an action $A$ with a view to $G$ if one has not put together the belief that $A$ is conducive to $G$ and one's pro-attitude towards $G$.

7 What follows from this is that the presence of a corresponding pro-attitude/belief pair is a condition of correction for a motive ascription. It is very common to hold, however, that our motives are always constituted by the corresponding pro-attitude/belief pairs. I will call this the Foreground View, in opposition to the Background View, according to which the presence of an appropriate pro-attitude/belief pair is a background condition for the correction of a motive ascription although the pair itself does not constitute the agent's motive. The Foreground View is problematic, mainly because it entails that the motives for which we act never correspond to the facts that provide us with reasons to act, which usually are not facts about our mental states (see Dancy, 2000, pp. 103-106). The argument of this paper, however, should work even if one holds the Foreground View. When pertinent, I will add notes to clarify how the argument should be understood by someone who holds the Foreground View. 
an incentive $I$ to perform action $A$, then she has a pro-attitude towards $G$ and a belief that $A$ is conductive to $G$ and puts them together in the appropriate way.

The motive-goal link holds in cases in which the agent's motive is provided by an incentive she recognizes. There are cases, however, in which despite recognizing several incentives to perform a particular action the agent's motive in performing the action in question corresponds to only one of those incentives.

\section{Multiple-incentives cases}

Consider the following example:

VOLUNTEER WORK: Mary is a really benevolent person. She cares for the well-being of others and does what she can to promote their well-being. One fine day she learns that a local soup kitchen is in need of volunteers. She has a few free hours that she could spend in the soup kitchen. She decides to volunteer there because it will relieve the suffering of people in need. As a matter of fact she also wants to be admitted into the University next semester and believes that volunteering increases her chances of being admitted. She is well aware of that, but that is not why she volunteers.

In this example Mary recognizes two incentives to volunteer at the soup kitchen: the fact that it will relieve the suffering of people in need and the fact that it will increase her chances of being admitted at the University. Her motive corresponds only to the former incentive, however. I will refer to cases such as this, in which the agent recognizes several incentives to perform an action and yet acts for a motive that corresponds to only one of those incentives, as multiple-incentives cases. ${ }^{8}$

The existence of multiple-incentives cases may be contested. One may hold that if an agent recognizes more than one incentive to perform action $A$, then her motive for doing $A$ must be a compound-motive that combines all the incentives she recognizes. The correct motive ascription in Mary case would then be "she volunteered at the soup kitchen because it would relieve the suffering of people in need and would increase her chances of being admitted at the University". And that would entail that her action aimed both at relieving the suffering of people in need and at furthering her admission at the University.

We do, however, assume that multiple-incentives cases are possible. First, is it simply a fact that we usually point out the motive for which an agent

8 If one holds the Foreground View, multiple-incentives cases must be understood as cases in which an agent performs an action $A$, has more than one pro- $A$ pair and only one of these pairs constitutes the motive for which she performed action $A$. 
acted even in cases in which the agent had several incentives to act as she did. Just think of how often people say things like "I did not do it for the money" (granted this is very often a false statement, but one that we assume can be true on occasion).

Second, it is often remarked that a truly virtuous person performs virtuous actions for their own sake. ${ }^{9}$ A truly benevolent person, for instance, performs a charitable action not because she will get something out of it, but for its own sake. That is not to say that in performing a charitable action the benevolent agent does not aim at a further end (namely, the promotion of the well-being of others). Rather it is to say that the benevolent person's action does not aim at procuring a personal advantage for herself. Given the motive-goal link, it follows that the motive for which a truly benevolent person performs a charitable action is not provided by the fact that it promotes a personal interest of hers (or by any fact that explains why the action promotes a personal interest of hers). If that is the case, then the benevolent person's motive to perform a virtuous charitable action is pure in that it does not include self-interested incentives and the same should be true of other virtues. But surely a virtuous person can recognize the self-interested incentives she has to perform a virtuous action. Mary is no less benevolent for having a desire to be admitted at the University and believing that volunteering is conductive to that goal (nor, if she falls short of full benevolence, could she come any closer to virtue by losing that desire or the associated belief). Neither self-denial nor ignorance of the advantages that may accrue from moral behavior are conditions of virtue, much less a path to it. Therefore, if virtuous agents do perform virtuous actions for their own sake, then multiple-incentives cases are possible.

Third, we recognize cases in which it is important that we do not act for an incentive that is available to us. Suppose you are in a loving relationship with a very rich person. Suppose further that you have a strong interest in financial stability and know that maintaining that relationship is an effective way to guarantee that. That provides an incentive for you to maintain your relationship (which entails the performance of a number of actions). But no one will doubt that it is perfectly intelligible that it should matter to our partner not only that you maintain your relationship out of love or mutual care but also that you do not maintain it out of love and financial interest. That is clearly not a demand that you stop caring about your own financial stability nor that you lose your knowledge about your partner wealth. Therefore, it reflects the belief that you 
can act out of love only, even though you have financial incentives to act in the same way. Indeed, it may be the case that an act can be considered a genuine act of love or friendship only if considerations of personal gain play no role in moving the agent to it (as an act of devotion to a person or a cause is one to which no consideration of personal gain is mixed).

Now, if there are multiple-incentives cases, it follows that the motives for which we act are not determined by the incentives we happen to recognize. And this, I shall now argue, entails two things: (i) that the goals at which our actions aim are not passively determined by the pro-attitude/belief pairs we happen to have and (ii) that we are not directly moved by pro-attitude/belief pairs.

\section{Multiple-incentives cases, Desires and the Goals of our Actions}

If an agent is moved to perform a particular action by her desire for a reward she believes she will get by so acting, then her action aims at getting her that reward. For instance, if one is moved to return a lost dog to its owners by one's desire for money combined with the belief that by returning the dog one is likely to get a reward, then one's action aims at getting that reward. And the same seems to apply to cases in which the agent is moved by several desires or pro-attitudes: if one is moved to perform a particular action by a desire to alleviate the suffering of people in need and by the desire to obtain a certain reward, then one's action aims both at relieving the suffering of others and at getting the reward. In general, the following entailment seems to hold:

DESIRE-GOAL LINK: If a pro-attitude towards $G$ combined with the belief that action $A$ is conductive to $G$ is part of what moved agent $P$ to perform action $A$, then $A$ aims at goal $G$.

Now, according to the Hydraulic Model, we are moved by our desires or pro-attitudes, combined with appropriate means-end beliefs. And given the thesis of compositionality, pro-attitude/belief pairs that favor the same action combine in motivating us to perform that action. Therefore, in combination with the desire-goal link, the Hydraulic Model entails that the goals at which a particular action $A$ aims are determined by the agent's pro- $A$ pairs. If we accept this consequence, however, we cannot account for multiple-incentives cases.

Consider Mary's case. She recognizes two incentives to volunteer: the fact that it will relieve the suffering of people in need and the fact that it will increase her chances of being admitted at the University. Nevertheless, if this is a genuine multiple-incentive case, the correct motive ascription is (i) "she 
volunteered because doing so would relieve the suffering of people in need" and not (ii) "she volunteered because doing so would relieve the suffering of people in need and would also increase her chances of being admitted at the University". But why is (ii) incorrect? This requires an explanation and given that Mary wants to be admitted at the University and believes that volunteering contributes to that goal, the only available explanation is this: as a matter of fact, her action does not aim at getting her to be admitted at the University. Given the motive-goal link, it follows that she did not volunteer because it would increase her chances of being admitted at the University, i.e., it follows that (ii) is incorrect. ${ }^{10}$

The problem, of course, is that if the goals an action aims at are determined by the pro-attitude/belief pairs in the agent's motivational set (i.e., the agent's set of pro-attitude/belief pairs) that favor the action in question, then this explanation is not available. In multiple-incentives cases the agent recognizes more than one incentive to act as she does. That entails that she has more than one pro-attitude/belief pair that favors the action she performs. If the goals at which our actions aim are determined by those pairs, it follows that the action in a multiple-incentive case aims at more than one goal, each one corresponding to one pro-attitude/belief pair that favors the action. In particular, it follows that Mary's action does actually aim at getting her to be admitted at the University (in addition to aiming at relieving the suffering of people in need).

The existence of multiple-incentives cases leads, therefore, to two important conclusions. First, that the goals at which action $A$ aims are not fixed by the pro- $A$ pro-attitude/belief pairs the agent happens to have (or, which is the same, that the goals action $A$ aims are not fixed by the incentives to perform $A$ the agent happens to recognize). Second, given that the Hydraulic Model, in conjunction with the desire-goal link, entails that the goals at which our actions aim are determined by our pro-attitude/belief pairs, the existence of multipleincentives cases shows the Hydraulic Model to be false - in particular, it shows that we are not directly moved by our pro-attitude/belief pairs. I elaborate these conclusions further in section 8 . In the next sections I address some objections to the argument just presented.

10 If one holds the Foreground View the question is why, given that Mary has two pro-attitude/belief pairs that recommend the action of volunteering, only one of these pairs constitutes her motive. The answer has to be that her action does not aim at the goal corresponding to the pro-attitude/belief pair that does not constitute her motive. 


\section{Davidson Causalism}

One could reconcile claim (A) - that we are moved by our pro-attitude/ belief pairs - with the claim that there are multiple-incentives cases, while accepting the desire-goal link, by rejecting (B) - the thesis of compositionality, according to which our pro- $A$ pairs combine in motivating us to perform an action $A$.

In order to deny (B) one does not have to hold that pro- $A$ pairs never combine to produce a stronger motivation to perform $A$, but only that in some cases, such as multiple-incentives cases, they do not combine. That cannot mean, however, that in this cases the agent is left with several isolated motivations to perform $A$ : we can make sense of the claim that providing a further incentive makes the agent more motivated to perform an action $A$, but not of the claim that providing a further incentive produces in the agent a further motivation to perform action $A$ but does not make her any more motivated to perform $A$. The suggestion must be, then, that in multiple-incentives cases some of the agent's pro-attitude/belief pairs simply do not motivate the agent - they are there, the agent recognizes the corresponding incentive, but they remain inoperative. This would allow one to claim that the goals at which an action $A$ aims are determined by the pro-attitude/belief pairs that actually moved the agent to perform $A$ while at the same time acknowledging the existence of multiple-incentives cases.

According to an interpretation of Davidson's causalism that is exactly his view. Davidson's argument, the interpretation goes, consists in pointing to multiple-incentives cases and claiming that causalism can account for them whereas non-causalism cannot: in these cases only one of the available proattitude/belief pairs causes the action. ${ }^{11}$ If only one of several pro- $A$ pairs caused action $A$, then it alone moved the agent. It must be the case that other pro- $A$ pairs the agent had remained inoperative in this case. In that way, the claim that we are moved by pro-attitude/belief pairs can be reconciled with the claim that multiple-incentives cases are possible, even if the desire-goal link is accepted.

One difficulty this view faces is to explain why some of the agent's proattitude/belief pairs fail to cause the action: why did they fail to play any part in bringing about the action if they were available and live, did not conflict with the pro-attitude/belief pair that actually moved the agent and, in many cases,

11 See, for instance, Dancy (2000, pp. 161-2), Wallace (2006, p. 61) and Dickenson (2007, pp. 3-4). Davidson clearly recognized multiple-incentives cases: "[...] you may err about your reasons, particularly when you have two reasons for an action, one of which pleases you and one which does not. For example, you do want to save Charles pain; you also want him out of the way. You may be wrong about which motive made you do it" (Davidson, 1980, p. 18). 
would move the agent in the absence of that pair? Given that we only have a genuine multiple-incentives case if the agent actually recognizes multiple incentives, the option of claiming that the agent failed to put together the inoperative pro-attitude/belief pairs is unavailable. And simply claiming that some of the agent's pro-attitude/belief pairs remained inoperative because they did not cause the action is uninformative. Objections along these lines have been put forward in the literature ${ }^{12}$ and I do not intend to press them further. ${ }^{13}$ Rather, I will argue that this interpretation of Davidson's view has unacceptable consequences concerning multiple-incentives cases, namely, that in these cases the agent's motivation is always out of line with the correct assessment (from her own perspective) of how desirable the action in question is.

According to Davidson a pro-attitude/belief pair rationalizes an action, under a particular description, if the performance of the action is reasonable in light of that pair. In order to explain what it is for an action to be reasonable in light of a set of pro-attitudes and beliefs Davidson appeals to the notion of practical reasoning. According to him, we should think of these attitudes as providing the premises for an argument whose conclusion is that the action is prima facie desirable (Davidson, 1980, p. 77). Consider, for instance, the case of someone that adds sage to the stew with the intention of improving its taste: the belief "adding sage to the stew will improve its taste" provides a corresponding premise and the desire to improve the taste of the stew provides the evaluative premise that "it is prima facie desirable to improve the taste of the stew" (Davidson, 1980, p. 78). To determine if an action is reasonable in light of set of desires and beliefs we have to weigh the various prima facie

12 See, for instance, Dancy (2000, pp. 161-163) and Dickenson (2007, pp. 13-4). Both hold that Davidson cannot provide an informative answer to the question "why did primary reason R1 caused the action and primary reason R2 did not, provided that both were available?". Dickenson suggests that Davidson could give content to that claim by introducing the notion of motivational strength and claiming that which among the agent's pro- $A$ pro-attitude/belief pairs caused her action $A$ is decided by the relative strength of the pairs (2007, pp. 15-6). I discuss this suggestion in the next section.

13 Let me just reject one way in which one could hope to explain how an agent can render a pro-attitude inoperative. Neil Sinhababu holds that a second-order desire to be moved exclusively by a particular first-order desire (what Frankfurt calls a "second-order volition" - see Frankfurt, 1971, p. 10) could effectively prevent other desires from moving the agent (Sinhababu, 2013, pp. 687-8). He holds that one such second-order desire, were it strong enough, could render all pro- $A$ desires except the one it favors inoperative. But this cannot be right. If a second-order desire to be moved to perform $A$ by a particular pro-attitude/belief pair could render other pro- $A$ pairs inoperative, then a strong enough second-order desire not to be moved to perform $B$ by a particular pro-attitude/belief pair should be able to render the pro- $B$ pair in question inoperative. That, however, is clearly is not the case. Think of someone who is addicted to a drug. This person has a very strong desire to take the drug. Suppose, however, that this person also wants very much not to be moved by that desire - the addiction has ruined her life and the thing she wants more in the world is to overcome it. Her second-order volition not to be moved by the desire for the drug is as strong as can be, but, unfortunately, we know that is not enough to render the desire for the drug inoperative. In many cases it is not even enough to diminish its strength. And the same goes for non-compulsive desires: the dieter's desire to have one more desert is not silenced by an opposing second-order desire nor is the philanderer's desire to cheat on his wife. 
judgments that can be derived from this set. If the prima facie judgments that are favorable to the action override the judgments that testify against it, then we can form the unconditional judgment expressed simply as "this action is desirable" (Davidson, 1980, p. 87). Presumably, when comparing incompatible courses of action, we can weigh the prima facie judgments favoring each one to determine which is more desirable.

Davidson also accepts thesis (C). ${ }^{14} \mathrm{He}$ claims that the following principle is self-evident: "if an agent wants to do x more than he wants to do y and he believes himself free to do either $\mathrm{x}$ or $\mathrm{y}$, then he will intentionally do $\mathrm{x}$ if he does either x or y intentionally" (Davidson, 1980, p. 23). In normal, non-akratic cases, therefore, the agent's motivation to perform an action will track her assessment of how desirable the action is: if actions $A$ and $B$ are incompatible, an agent takes $A$ to be more desirable than $B$ and she is not incontinent, then she will perform $A$ and not $B$ (if she performs either), and that means, given (C), that she is more motivated to perform $A$ than $B$.

Now consider Mary's case. Suppose her concern for the well-being of others provides her with a motivation that is strong enough to get her to volunteer. According to the view we are considering, given that hers is a multiple-incentives case, the pro-attitude/belief pair composed of her desire to be admitted at the University and her belief that volunteering would increase her chances of achieving that goal remains inoperative even though she is well aware of the corresponding incentive. If nothing new comes up she will volunteer and her action will be aimed solely at relieving the suffering of people in need. But she finds out that her volleyball practice was moved to the same time at which she would volunteer at the soup kitchen (suppose that was the only time she could do it). She is quite passionate about volleyball and attending the practice is also a way for her to get in touch with some friends and to stay fit - given these incentives she acquires a motivation to attend the practice that is slightly stronger than the motivation to volunteer derived from her concern for the well-being of others. Now let us suppose that were Mary to weigh all the incentives favoring the option of volunteering and the option of attending the practice, she would conclude that the option of volunteering is more desirable. Two things could happen at this point then: Mary could simply be moved by the strongest operative motivation and attend the volleyball practice or she could

14 This is no accident: an agent can have, and often has, pro-attitude/belief pairs that favor incompatible actions and if one holds that we are moved by those pairs it seems that the only way to explain why an agent performed action $A$ rather than $B$, given that she had pro-attitude/belief pairs favoring each of the alternatives, is to claim that the pro-attitude/belief pairs favoring $A$ were stronger than the ones favoring $B$. This point is endorsed by Mele, another prominent causalist (see Mele, 1992, p. 83). 
be prompted to reflect about her options and weigh the available incentives. If the former, she would be lead to act in a way that is sub-optimal from the point of view of the incentives she recognizes. If the latter, she would come to declare the option of volunteering more desirable than the option of attending volleyball practice. And then two things could happen: either her motivation to volunteer would fall in line with her assessment of how desirable the action is or it will not. If the latter, then she will act akratically against her best judgment. If the former, she becomes more motivated to volunteer than she was before and that means that her previously inoperative pro-attitude/belief pair becomes operative. This is by itself an odd result: ordinarily, an agent does not become more motivated to do $A$ simply because she found out that in order to do it she must give up something she wants almost as much as she wants to do $A$. That, however, seems to be what happened to Mary, for she did not come to recognize new incentives she was previously unaware of nor did she come to a fuller appreciation of the good she could do or of the benefits she could accrue. More importantly, however, since she did not become aware of any new incentives, it follows that her previous, lesser motivation to volunteer, was out of line with the correct assessment, from her own idiosyncratic perspective, of the action's desirability. And that means that the possibility of her acting with a view solely to an altruistic goal rested upon a flawed or incomplete assessment of the desirability of the option of volunteering or upon a quasi-akratic misalignment between her motivation and her judgment of desirability. That becomes clearer if we suppose that the volleyball practice is again moved so that now Mary can both volunteer and attend the practice. Now she has already consciously entertained the judgment that volunteering is more desirable than attending the practice, but she will be able to volunteer with a view solely to an altruistic goal only by rendering her self-interested pro-attitude/belief pair inoperative and thus dialing down her motivation, so that as a matter of fact it becomes weaker than her motivation to attend volleyball practice - and then her motivation will be out of line with her judgment.

Surely, however, (i) the possibility of multiple-incentives cases does not rest upon flawed or incomplete assessments of desirability. The benevolent person can perform charitable actions for their own sake even if she is aware of the personal advantages that may result from so acting and correctly assess the balance of incentives - a joyful realization that this balance favors the option of helping others is by no means incompatible with true virtue. And (ii) it is hardly the case that the possibility of multiple-incentives cases rests upon a misalignment between motivation and judgment of desirability. Given thesis (C), Davidson must assume that in normal, non-akratic cases motivation tracks 
the agent's judgments of desirability and there is no reason to suppose that multiple-incentives cases deviate from this rule or that in these cases agents present some kind of quasi-akratic flaw in motivation. I conclude, therefore, that Davidson's causalism cannot render the view that we are moved by our proattitude/belief pairs compatible with the claim that there are multiple-incentives cases.

\section{Motivational Strength}

A way in which to reconcile the Hydraulic Model with the claim that there are multiple-incentives cases is to deny the desire-goal link. One could claim that the goals at which an action $A$ aims at are a function not only of what pro- $A$ pairs moved the agent but of how strong they are. In particular, one may hold that the goal $A$ aims at does not correspond to the goals associated with each of the pro- $A$ pairs in the agent's motivational set but rather to the goal associated with the pro- $A$ pair that has some kind of preponderance in that set. A way to cash out that suggestion (and, I believe, the most promising one) is to hold that:

SUFFICIENCY CRITERION (SC): An agent performs an action $A$ with a view only to goal $G$ even if she is moved by several pro-attitude/belief pairs if, and only if, (i) the agent performs $A$, (ii) the agent desires $G$ and believes $A$ to be conductive to $G$ and (iii) this pro-attitude/belief pair is strong enough to motivate the agent to perform $A$ in any counterfactual situation in which the circumstances of action are the same but the agent does not have any of the other pro-attitude/belief pairs that favor the performance of action $A$ in her actual circumstances.

This proposal clearly involves the rejection of desire-goal link for it entails that one can be moved by several pro-attitude/belief pairs without it being the case that one's action aims at corresponding goals. And, if it is correct, it provides a way in which to reconcile the claim that the goals at which an action $A$ aims are determine by the agent's pro- $A$ pairs (particularly by their relative strengths) with the existence of multiple-incentives cases

The appeal of the proposal is clear. Consider the volunteer work case. SC entails that in this case we are authorized to claim that "Mary volunteered because doing so would relieve the suffering of people in need" only if it is true that Mary would have acted in the same manner even if she did not want to be admitted at the University or did not believe that volunteering would increase her chances of admission. And that seems reasonable enough. Nevertheless, $\mathrm{SC}$ faces serious problems.

First, it cannot account for some multiple-incentives cases, namely, those in which more than one pro- $A$ pair is strong enough to motivate the agent to 
perform action $A$. For instance, it may be true that Mary would have acted the way she did even if she did not want to be admitted at the University and thus that, according to $\mathrm{SC}$, her sole goal in volunteering was to relieve the suffering of these in need. But it may be also true that she would have acted in the same way if she did not care for the well-being of others - and, according to SC, that would entail that she volunteered with a view solely to being admitted at the University. In this case, SC would either lead to a contradiction or, in a charitable reading, entail that Mary's action aimed at a compound-goal. We could only claim that she acted with a view to the altruistic goal alone if the self-interested incentive prompting her to volunteer was not strong enough to motivate her to volunteer on its own. And that would be the case only if she had a set of pro-attitude/belief pairs prompting her to perform an action incompatible with the option of volunteering that was stronger than the selfinterested pro-attitude/belief pair that prompts her to volunteer. That is to say that whether or not Mary acts with a view to the altruistic goal alone depends on how strong are the pro-attitude/belief pairs that prompt her to perform alternative incompatible actions. This introduces a problem of irrelevance. Suppose that Mary wants to spend more time practicing volleyball (a sport about which she is passionate), that this option is incompatible with the option of volunteering and that she is not considering any other alternative course of action. According to the suggestion under consideration, assuming that her concern for the well-being of others is strong enough to move her on its own, she volunteers with a view to a compound-goal if the set of pro-attitude/belief pairs prompting her to dedicate more hours to volleyball is weaker than the proattitude/belief pair composed of the desire to be admitted at the University and the belief that volunteering increases her chances of admission. However, if the former set is stronger than the latter pair, then her action of volunteering aims only at the altruistic goal. This means that her action could go from aiming at a compound-goal to aiming at a pure altruistic goal simply because her desire to dedicate more hours to volleyball became stronger. But that cannot be right: why should the fact that Mary became more passionate about volleyball make it the case that her act of volunteering does not aim at securing a personal advantage for her, if she still recognizes the same incentives and is moved by the same desires?

In order to avoid this problem one could restrict SC to certain goals. For instance, one could hold that we ascribe a pure altruistic goal to an action when the conditions specified by SC obtain because we are willing to ascribe a pure altruistic motive to altruistic actions we deem praiseworthy and, as a matter of fact, we deem altruistic actions praiseworthy when the agent was moved by 
an altruistic desire that would have moved her even if she had not recognized the self-interested incentives she did recognized. And, one would continue, for this reason SC holds when goal $G$ is an altruistic goal but not when it is a self-interested goal. However, even if we restrict SC to altruistic goals in this manner we should reject it for it leads to arbitrary goal attributions.

Consider Mary again. She recognizes two incentives to volunteer at the soup kitchen, one altruistic the other self-interested, and has, therefore, the corresponding pro-attitude/belief pairs. She actually volunteers and, let us suppose, she acts in the same manner in the counterfactual circumstance in which she does not recognize the self-interested incentive. According to the restricted version of SC, therefore, she volunteers in order to relieve the suffering of people in need and her action is commendable. Now consider Megan. She recognizes the same incentives as Mary and, let us assume, the pro-attitude/ belief pairs underlying these incentives are exactly as strong as Mary's proattitude/belief pairs. Megan also volunteers at the soup kitchen. Nevertheless, Megan does not act in the same way in the counterfactual situation in which she does not recognize the self-interested incentive to volunteer. Let us suppose that in this counterfactual situation Megan decides to spend her few free hours practicing volleyball instead of volunteering. According to the restricted version of SC, therefore, it is not the case that Megan volunteers in order only to relieve the suffering of people in need (at the very least her action aims at a compoundgoal that includes a self-interested goal) and, therefore, her action is not as commendable as Mary's. But does that counterfactual difference provides any ground to ascribe different goals to Mary's and Megan's action? What is the actual difference between them that grounds the counterfactual difference? If we are committed to the Hydraulic Model, it must be the case that Mary's altruistic pro-attitude/belief pair was stronger than the set of pro-attitude/belief pairs favoring the option of practicing volleyball, while for Megan the contrary is true. Given the stipulation that the altruistic desire was equally strong in Mary and Megan (and that their beliefs are the same), it must be the case that the set of pro-attitude/belief pairs favoring the option of practicing volleyball is weaker in Mary than in Megan. The fact is then, let us suppose, that Megan is simply more passionate about volleyball than Mary. That means that in deciding to volunteer Megan had to overcome a stronger opposing desire. Other than that, the pro-attitude/belief pairs that moved her were exactly the same that moved Mary and exactly as strong. Why should we say then that they acted with a view to different goals? The natural thing to say is that they acted with a view to the same goals, and for the same motives, although Megan had to overcome a slightly stronger temptation to act otherwise. Our interlocutor 
could insist that we ascribe a pure altruistic goal only to Mary because we judge her action more praiseworthy than Megan's on account of the fact that Mary would have acted in the same way even without any self-interested incentive. But, given that the only actual difference between Mary and Megan that a supporter of the Hydraulic Model can identify is that Megan is more passionate about volleyball, that is the only ground on which to claim that her action is less praiseworthy than Mary's. And that is simply absurd: surely Megan's action would not become any more praiseworthy on account of her losing her enthusiasm for volleyball (assuming her concern for others remains the same) nor is it the case that morality requires her to become less passionate about the sport. We should, therefore, reject SC.

\section{Shaping our Desires}

Bernard Williams, in his seminal paper "Internal and External Reasons", claims that our motivational set is highly plastic. Not only can we create new derivative desires by drawing means-end relations and suppress desires by showing that they rest of false beliefs, we can also, for instance, loose or acquire desires by exercising our imagination to get a more concrete sense of what would be involved in satisfying them (Williams, 1981, pp. 104-5). Deliberation, Williams claims, while being controlled by the agent's motivational set, can change it dramatically - it may add and exclude non-derivative elements from it, and, since it can do that, there should be no difficulty in admitting that it can change the relative strength of these elements. ${ }^{15}$

If that is correct, then agents have an active role to play in determining the configuration of their motivational sets and, therefore, in determining their actions, even if we accept the claim that we are moved by our pro-attitude/belief pairs. It is illuminating to attend to the fact that this is not enough to account for the possibility of multiple-incentives cases. If we are moved by pro-attitude/ belief pairs and the desire-goal link holds, the fact that our motivational set is highly plastic does not provide an explanation of how one can desire $G$, believe $A$ to be an effective means to $G$ and yet do $A$ without aiming at $G$. It could provide such an explanation only under the assumption that in multipleincentives cases the agent temporarily suppresses all but one of her pro- $A$ attitudes or desires. But that is very implausible: there is no reason to suppose that a benevolent person, for instance, can only perform a benevolent act for its own sake by temporarily ceasing to care for the personal advantages she 
knows will follow from that act. This teach us an important lesson: in order to account for multiple-incentives cases it is not enough to assume that agents can actively determine their desires and, through them, their own behavior; rather we have to assume that agents can actively determine the goals at which their actions aim (instead of passively letting those goals be determined by the proattitude/belief pairs they happen to have).

\section{Why do we need the notion of Will?}

In a multiple-incentives case the agent recognizes more than one incentive to act but the correct motive ascription mentions only one of these incentives. The trouble is to explain why the correct motive ascription does not incorporate the other incentives. Given that the agent recognizes these incentives and, therefore, has the corresponding pro-attitude/belief pairs the only available explanation seems to be this: as a matter of fact, her action did not aimed at the goals associated with these incentives. This answer is unavailable as long as we assume that the goals at which our actions aim correspond to the goals associated with the incentives to act we recognize. The first conclusion we can draw from the existence of multiple-incentives cases, therefore, is that the goals at which an action $A$ aims are not passively determined by the pro- $A$ pairs the agent happens to have. Rather, I will now suggest, we should conceive of agents as endowed with the capacity to actively determine the goals at which their actions are directed and, given the motive-goal link, to actively determine the motive for which they act.

I refer to such capacity as the "will". An agent's will determines the agent's goal in performing a particular action by forming or acquiring intentions. The content of these intentions can be expressed as "I intend to do $A$, in circumstances $C$, in order to $G$ ". The $G$-slot specifies the goal action $A$ aims at when the intention is executed. To say that an agent has the capacity to actively determine the goal her action aims at is simply to say that the content of $G$-slot is not determined by her pro- $A$ pro-attitude/belief pairs but rather by an exercise of the will. In particular, in multiple-incentives cases, an agent may form the intention of performing action $A$ in order only to $\mathrm{G}$, even though she recognizes a further incentive to perform $A$, associated with goal $E$. Mary, for instance, forms the intention expressed by "I intend to do $A$ in order to relieve the suffering of people in need" and not an intention that incorporates the goal of increasing her chances of being admitted at the University, even though she recognizes both incentives and has the corresponding pro-attitude/belief pairs. According to this view, an incentive becomes an agent's motive to act only to 
the extent the goal associated with it is incorporated into the agent's intention. ${ }^{16}$

To give content to the idea that agents can actively determine the goals at which their actions aim we have to develop a conception of the will and the intentions it produces. A Kantian view identifies the will with practical reason and conceives of intentions as identical with or determined by practical judgments about what we have reason to do. Although I cannot argue here for this claim, I believe this conception is misguided, mainly because it cannot account for the possibility of akratic intentions and for the fact that we can form definite intentions in situations in which we cannot arrive at a definite conclusion about what we have, all things considered, reason to do. ${ }^{17}$

A better option is to conceive of intentions as the state of being settled on a plan and of the will as a capacity to settle on plans of action. We may think of plan as an ordered pair \{goal; strategy\} where the content of strategy-slot represents steps to be taken, in a particular order, to achieve the goal. Having an intention is simply a matter of having the attitude of being settled on directed towards a particular plan. ${ }^{18}$

When an agent executes a plan the contents of the strategy-slot guide her action. The possibility of this guidance is dependent upon the agent ability to monitor her action in light of the plan. In order to be able to follow a plan you have to be able to determine whether or not you have performed the step you are endeavoring to perform and whether it achieved the sub-goal at which it was aimed and you must be able to adjust your behavior in light of the feedback you receive (deciding, for instance, whether to go on to the next step, to try to perform the current step again, to modify your plan, to give up, etc.). When something does not goes as planned, as when you find that you cannot execute one of the steps of the plan or it fails to produce the expected effect, the execution of the plan stops in its tracks and you have the options of re-executing the step in question, modifying the plan or abandoning it. When agents halt the execution of a chain of actions and adopt one of these measures we have indication that they were monitoring their action in light of a plan and get some insight into the content of the plan. Thus suppose you have a simple

16 The thesis that incentives only become motives when they are incorporated into the agent's intention has a Kantian ring to it. Kant notoriously held that an incentive moves one to action only in so far as it is incorporated into one's maxim (RGV, 6: 24, 73). Herman claims that an incentive becomes a motive only when incorporated into the agent's maxim (Herman, 1993, pp. 11-12). See also Allison (2011, pp. 114-5). It should be noted, however, that Herman and Allison identify incentives with desires and adopt the Foreground View. Furthermore, they hold that one's maxim reflects one assessment of one's reasons, a view to which I am not committed. See also Wallace (2006, pp. 58-62).

17 For a discussion of these objections see Watson (2003).

18 This view of intentions is defended by Mele (see 1992, p. 150). See also Bratman (1999). 
plan: your goal is to read your emails and your strategy is to go to your office, open your notebook, type in our login and password and so on. Suppose you go to your office, grab your notebook, open it and it does not turn on as you expected it would. If you are an able plan-follower you must by now know that you performed a step of your plan and it did not accomplished the expected sub-goal. You must also realize that you cannot move on to the next step and you have to be able to identify the options available to you: you may try to perform the same step again (opening and closing the notebook), or you could modify your plan (say, adding the step of clicking on the notebook's power button) or you could simply give up your goal of accessing your email. Suppose that being a reasonable person you go with the second option and you manage to achieve the sub-goal of turning on the notebook. ${ }^{19}$ Being aware of that you move on with your plan and finally you read your emails. At this point an able plan-follower should be in a position to realize she has achieved her goal, register that information and declare her plan a success, which means that she can stop monitoring her behavior in light of that plan.

If we conceive of intentions in this way, then the difference between the intention of doing $A$ in order to $G$ and doing $A$ in order to $G$ and $E$ is a difference in the content of the plan on which the agent has settled. If one has the former intention then the plan one has settled on is represented as $\{G ; A\}$, if the latter then $\{G$ and $E ; A\}$. Now, obviously, as far as the actions performed in executing these plans are concerned, there is no difference between them. But there is a real difference in the way these agents monitor their behavior in light of each of these plans and that gives content to the idea that they are aiming at different goals. The agent that aims at the compound-goal has to monitor whether or not her actions do achieve goal $E$ and will be prompt to reconsider her plan if her strategy does not succeed in bringing about $E$, whereas the same is not true of the agent with the single-goal plan.

If an agent can adopt a single-goal plan even when she knows that the actions she will execute promote another goal she happens to desire, prize or want, then, given the desire-goal link, it follows that she is not directly moved by her pro-attitude/belief pairs, pace the Hydraulic Model. This is the second important conclusion we can draw from the existence of multiple-incentives cases. But if one is not directly moved by one's pro-attitude/belief pairs, how is one's behavior determined? One option is to suppose that agents are moved by their pro-attitude/belief pairs but that by setting the goals their actions aim

19 Notice that there is no need to assume that the agent in this example has consciously formulated the plan in question. That she is following the plan, even if she has not consciously considered it, is indicated by the way in which she monitors her actions and adjusts her behavior in response to unexpected results. 
at they can render some of these pairs inoperative. This is suggested by the combination of the idea that the goals our actions aim at are actively determined by an exercise of the will with the desire-goal link: by not incorporating a particular goal into her intention the agent makes it the case that a pro-attitude/ belief pair that she has takes no part in moving her, i.e., remains inoperative. ${ }^{20}$ But that is an odd consequence: if desires can move us, how can the will render them inoperative? ${ }^{21}$ The second, better option, is to assume that pro-attitude/ belief pairs do not have intrinsic motivational force: agents endowed with a will are not moved by motivational forces within them, rather they form intentions (i.e., settle on plans) by exercising their will and execute them. There is still room to claim that in a particular situation an agent was moved by a desire, but that claim has to be understood as a motive ascription, which identifies the agent's motive with the fact that she had the desire in question.

Surely, both the conception of the will as a planning capacity and the claim that agent's endowed with a will are not moved by their pro-attitudes but rather execute plans they have settled on have to be further elaborated. How do agents settle on a particular plan? How do desires interfere with the workings of the will? ${ }^{22}$ If we are not moved by desires, why do we sometimes fail to execute our plans? These are some of the questions that have to be answered before we can be satisfied with a volitionalist model of agency. But that is a task for another time. The goal of this paper was to argue that the best way to account for the existence of multiple-incentives cases is to conceive of agents as endowed with a will and, thus, as capable of setting the goals for their actions. That much I hope to have accomplished.

\section{References}

ALLISON, H.E. "Kant's Groundwork for the Metaphysics of Morals". New York: Oxford University Press, 2011.

BRATMAN, M.E. "Intention, Plans, and Practical Reason". Cambridge: Harvard University Press, 1999.

20 For a suggestion along these lines see Herman (1993, pp. 10-13).

21 Furthermore, this view will lead to the same troublesome consequences discussed in section 5.

22 It may be wise to reject here a particular view about the motivational relevance of desires. One could suppose that even though desires do not move us to action directly, they directly determine what action we intend to perform: the strongest set of pro-attitude/belief pairs leads us to form the intention of performing the action it favors and, through a different process, we incorporate a specific goal to that intention. If this view were correct it would be the case that we are moved to act by all the desires in the strongest set of pro-attitude/ belief pairs. But given the desire-goal link and the claim that our intentions set the goals our actions aim at, it would follow that only the desires associated with the goal incorporated into the intention moved us to act. While we hold on to the desire-goal link, therefore, the claim that our intentions are directly determined by the power struggle between our pro-attitude/belief pairs leads to contradiction. 
DANCY, J. "Practical Reality". New York: Oxford University Press, 2000.

DAVIDSON, D. "Essays on Actions and Events". New York: Oxford University Press, 1980.

DICKENSON, J. "Reasons, causes, and contrasts". Pacific Philosophical Quarterly, Vol. 88, 2007, pp. 1-23.

FRANKFURT, H. "Freedom of the Will and the Concept of a Person". The Journal of Philosophy, Vol. 68, Nr. 1, 1971, pp. 5-20.

HERMAN, B. "On the Value of Acting from the Motive of Duty". In: Herman, B. The Practice of Moral Judgment. Cambridge: Harvard University Press, 1993, pp. 1-22.

MCDOWELL, J. "Non-Cognitivism and Rule-Following”. In: McDowell. Mind, Value and Reality. Cambridge, Harvard University Press, 2002, pp. 198-218.

"Are Moral Requirements Hypothetical Imperatives?". Proceedings of the Aristotelian Society, Vol. 52, 1978, pp. 13-29.

MELE, A. R. "Springs of Action”. New York: Oxford University Press, 1992.

NAGEL, T. "The Possibility of Altruism". Princeton: Princeton University Press, 1978. SCHROEDER, M. "Slaves of the Passions". New York: Oxford University Press, 2007. SCHUELER, G. F. "The Humean Theory of Motivation Rejected". Philosophy and Phenomenological Research, Vol. LXXVIII, Nr. 1, 2009, pp. 103-122.

SINHABABU, N. "The desire-belief account of intention explains everything". Nous, Vol. 47, Nr. 4, 2013, pp. 680-696.

SMITH, M. "The Moral Problem". Oxford: Blackwell Publishing, 1994.

"Rational Capacities, or: How to Distinguish Recklessness, Weakness, and Compulsion". In: Stroud, S. \& Tappolet, C. (eds). Weakness of Will and Practical Irrationality. New York: Oxford University Press, 2003, pp. 17-38.

VELLEMAN, J. D. "What Happens When Someone Acts?". Mind, Vol. 101, 1992, pp. 461-481.

WALLACE, J. "Normativity and the Will”. New York: Oxford University Press, 2006. WATSON, G. "The Work of the Will”. In: Stroud, S. \& Tappolet, C. (eds.), Weakness of Will and Practical Irrationality. New York: Oxford University Press, 2003, pp. 172-200. WILLIAMS, B. "Internal and External Reasons". In: Williams, B. Moral Luck: Philosophical Paper 1973-1980. Cambridge: Cambridge University Press, 1981, pp. 101-113. 